\title{
Paraffin/red mud phase change energy storage composite incorporated gypsum-based and cement-based materials: microstructures, thermal and mechanical properties
}

Zhiyong Liu ${ }^{1,2,3,4 *}$, Shu Zhang ${ }^{2}$, Dan $\mathrm{Hu}^{1}$, Yunsheng Zhang ${ }^{4}$, Henglin $\mathrm{Lv}^{2,3}$, Cheng Liu $^{5}$, Yidong Chen ${ }^{1}$, Juan Sun ${ }^{1}$

(1. State Key Laboratory of Geomechanics and Deep Underground Engineering, China University of Mining and Technology, Xuzhou 221116; China

2. Jiangsu Key Laboratory of Environmental Impact and Structural Safety in Engineering, China University of Mining and Technology, Xuzhou 221116; China;

3. JiangSu Collaborative Innovation Centre for Building Energy Saving and Construct Technology, Xuzhou 221116; China

4. Jiangsu Key Laboratory for Construction Materials, Southeast University, Nanjing 211189, China

5. Department of Civil, Environmental and Geomatic Engineering, University College London, London WC1E 6BT, UK)

*Corresponding author: Zhiyong Liu, Tel: 086-516-83590666, E-mail address: liuzhiyong0728@163.com

\begin{abstract}
In this study, paraffin/red mud phase change energy storage composites were fabricated at 4 mix proportions with paraffin to red mud ratios of 0.4:0.6, 0.45:0.55, 0.5:0.5, and 0.55:0.45 by a mixed mill-heating method. Scanning electron microscopy (SEM) and Fourier transform infrared (FT-IR) results reveal that paraffin flows well into red mud pores and has good compatibility. The differential scanning calorimetry (DSC) results reveal that the melting temperatures of the paraffin/red mud phase change energy storage composite vary from $75^{\circ} \mathrm{C}$ to $85^{\circ} \mathrm{C}$, and the latent heat
\end{abstract}


value is approximately $25 \sim 40 \mathrm{~J} / \mathrm{g}$. High thermal stability is observed by the thermogravimetric analysis (TG) method. The Brunauer Emmett Teller (BET) isotherms, laser particle sizer, X-ray diffraction analysis (XRD), and laser Raman spectrograph (LRS) show that the phase change energy storage composite does not produce a new material from the raw materials and that the material has a stable performance. Furthermore, the paraffin/red mud phase change energy storage composite was incorporated into the cement-based and gypsum-based materials at $10 \%, 20 \%$, and $30 \%$ weight. The heat storage performance can be improved remarkably with an increase in the addition of phase change energy storage composite replacement. The compressive strength change is minimal with the addition of $10 \%$ and $20 \%$, and the compressive strength decreases by nearly $40 \%$ with the addition of 30\%. The paraffin/red mud phase change energy storage composite has a large influence on the flexural strength.

Key words: Paraffin; red mud; phase change energy storage; cement-based materials

\section{Introduction}

Phase change energy storage materials are one of the most effective energy storage methods. Phase change energy storage materials release (or store) energy with exothermic or endothermic characteristics, and have the advantages of high heat storage and small changes in latent heat. At a constant temperature, phase change energy storage materials can store or release energy during a phase change. At present, phase change energy storage technology has a wide range of applications in many fields, such as solar thermal utilization, industrial waste heat, waste heat recovery, energy-saving heating, cooling buildings and other fields ${ }^{[1-3]}$. Phase change energy storage materials have satisfactory performances, and they have been attracting increasing attention from all over the world. Phase change energy storage materials can be classified as organic phase change composite materials and inorganic phase change composite materials. Organic phase change materials are mainly paraffin, acetic acid and other organic matter, and inorganic phase change materials are mainly 
crystalline hydrated salts, molten salts, metals or alloys ${ }^{[4-5]}$. Paraffin is a phase change thermal storage material, that has a large phase transition temperature range $\left(10 \sim 80^{\circ} \mathrm{C}\right)$, high phase change enthalpy $(200 \sim 300 \mathrm{~J} / \mathrm{g})$, large energy storage density, moderate price, and stable chemical properties. However, leakage of phase change materials during the phase change process limits its application to some extent. To overcome this problem, a matrix material is introduced to fabricate a stable phase change material with paraffin. The phase change material is created with a microcapsule container, such as a polymer microcapsule shell. Microcapsules can isolate the phase change material from the external environment and reduce the reaction between the phase change material and the external environment. $\mathrm{Li}^{[6]}$ et al. used in situ emulsification to fabricate a phase change material, and $\mathrm{SiO}_{2}$-coated paraffin microcapsules were prepared by interface hydrolysis and polycondensation of tetraethylorthosilicate (TEOS). The latent heat of fusion and solidification latent heat of the resultant material were $45.5 \mathrm{~J} / \mathrm{g}$ and $43.8 \mathrm{~J} / \mathrm{g}$, respectively. During the preparation of the microcapsules, the chemical reaction process is complex, difficult to control and costly. In recent years, adding nanoparticles or metal oxide particles to a base fluid has been used in thermal engineering. Ghalambaz $\mathrm{M}^{[7]}$ et al. studied the melting of nanoparticle-enhanced phase change materials in a square cavity, using the finite element method. Jegadheeswaran ${ }^{[8]}$ et al. investigated the thermal behaviour of nano-copper/paraffin phase change materials by numerical simulations. The results showed that the heat-release rate of the phase change composite material decreased by $28 \%$ and the thermal efficiency improved by $12 \%-15 \%$ when the volume fraction of nanocopper was $0.1 \%$. Porous sorption materials, such as perlite, diatomite, and montmorillonite ${ }^{[9-13]}$, are commonly used as the matrix material to prepare phase change composite materials with paraffin. Pincemin ${ }^{[14]}$ et al. prepared paraffin/graphite phase change energy storage composite materials using expanded graphite adsorption on paraffin. The results show that paraffin can significantly improve the thermal conductivity, and the thermal conductivity was $4 \sim 70 \mathrm{~W} /(\mathrm{m} \cdot \mathrm{K})$.

As a type of porous material, red mud is a solid residue extracted from alumina production enterprises. Generally, producing $1 \mathrm{t}$ of alumina will produce $1 \sim 2 \mathrm{t}$ of red 
mud. There are tens of millions of tons of abandoned red mud in the world. The production of a large amount of red mud has many direct and indirect impacts on human production and life. Red mud is strongly alkaline ( $\mathrm{pH}$ value is of 10-12), and red mud is mostly buried or deposited into the sea, causing pollution of soil, water and other sources. Therefore, a better use of red mud is needed. At present, red mud, as a raw material, is mainly used in building materials and environmental remediation ${ }^{[15-16]}$. Tsakiridis $\mathrm{P}^{[17]}$ et al. characterized the microscopic performance and chemical analysis of cement with $3.5 \%$ red mud added and ordinary cement; the results showed that adding $3.5 \%$ red mud had no effect on the microstructure of the cement. Senff $\mathrm{L}$ ${ }^{[18]}$ et al. studied the influence of red mud incorporation on mortar properties. Red mud incorporation affects the rheological properties of mortar. When the percentage of red mud is over $20 \%$, the mortar hydration heat begins to decrease. Pulford I D et al. ${ }^{[19]}$ showed that red mud has the ability to remove various pollutants from water. Red mud can be used to prepare adsorption materials for water treatment to remove heavy metal ions and anions in wastewater ${ }^{[20]}$. Red mud has the properties of porous materials and has the advantages of having a large specific surface area, large activity, strong adsorption capacity, moderate price, easy preparation and consumption of a large amount of solid waste ${ }^{[21]}$. Therefore, red mud can be used as a matrix material to prepare paraffin phase change materials.

In this paper, a paraffin/red mud phase change energy storage composite was prepared by a mixed mill-heating method. Then, SEM and FT-IR were used to characterize the microstructure and chemical compatibility of the raw red mud material and the paraffin/red mud phase change energy storage composites. The specific surface area was studied by $\mathrm{N}_{2}$ adsorption-desorption Brunauer Emmett Teller (BET) isotherms. The particle size distribution was characterized by a laser particle size analyser. The chemical composition and phase of the raw materials and phase change energy storage composites were characterized by XRF, LRS and XRD. The thermal reliability and durability of the paraffin/red mud phase change energy storage composites were measured by differential scanning calorimetry (DSC) and thermogravimetry (TG) analyses. Finally, the phase change energy storage materials 
were added to gypsum and cement paste at mass fractions of $10 \%, 20 \%$ and $30 \%$ to measure the thermal conductivity and mechanical properties.

\section{Experimental methods}

\subsection{Materials}

One of the raw materials used for the experiments was paraffin, which is a mixture of hydrocarbons extracted from certain distillates of petroleum, shale oil or other bituminous mineral oils consisting mainly of solid paraffin and odourless, white, translucent solids. The origin of the paraffin used in the experiment was Jiangsu, and the main elements were $\mathrm{C}$ and $\mathrm{H}$. The red mud used in the experiment was supplied by Luoyang Longmen Coal Industry Co., Ltd. It is generated from alumina extraction through the Bayer process. Cement and $\beta$-gypsum were supplied by Jiangsu Xuzhou.

The chemical composition of the red mud, cement, and $\beta$-gypsum was characterized by X-ray fluorescence spectrometry (XRF). The instrument used was an X-ray fluorite spectrometer manufactured by Bruker, S8 TIGER. The samples were dried at $105{ }^{\circ} \mathrm{C}$ for $2 \mathrm{~h}$ before testing. The results are shown in Table 1.

\subsection{Preparation of the phase change energy storage composites}

In this study, the phase change energy storage materials were prepared by a mixed mill-heating method. The red mud and paraffin were weighed to $30 \mathrm{~g}$, and 4 proportions of paraffin, i.e., red mud of 0.4:0.6 (1\#), 0.45:0.55 (2\#), 0.5:0.5 (3\#), and 0.55:0.45 (4\#), were prepared. The mixed red mud and paraffin were ground in a

grinder for $2 \mathrm{~h}$, and then, the mixed material was placed in an oven and heated at $80{ }^{\circ} \mathrm{C}$ for $4 \mathrm{~h}$. After that, the dried material was placed in a grinder and ground for an additional $2 \mathrm{~h}$. Finally, the prepared paraffin/red mud phase change energy storage composite was added to gypsum and cement to prepare a $3 \times 3 \times 5 \mathrm{~cm}$ sample to test the thermal conductivity and mechanical properties.

\subsection{Characterization of the phase change energy storage composites}

The microstructures of the raw materials and paraffin/red mud phase change energy storage composite were characterized by SEM. The instrument was a 
QuantaTM 250 microscope manufactured by the American company FEI. The magnification range was 6 to 1 million times, and the accelerating voltage was $0.2-30$ $\mathrm{kV}$. BET and laser particle size analysers were used to characterize the specific surface area, internal pore size and particle size of the raw materials and phase change energy storage materials. The BET experiment was carried out using QuadraSorb Station 1 manufactured by Quantachrome. The raw material and paraffin/red mud phase change energy storage composite adsorption-desorption isotherms were measured under $\mathrm{N}_{2}$. Before testing, degassing was performed to remove moisture and other gaseous impurities from the samples. The particle-size distributions were determined using a particle size analyser (Jinan Winner Particle Instruments Incorporated Winner3003).

The chemical composition and phase composition of the raw materials and paraffin/red mud phase change energy storage composites were characterized by LRS and XRD. The LRS is produced by German Brook (Bruker), and the model is Senterra. The XRD instrument is produced by German Brook (Bruker), and the model is D8 ADVANCE. The chemical stability of the samples was characterized by FT-IR spectroscopy. The manufacturer of the FT-IR spectrometer is German Brook (Bruker), and the model is VERTEX $80 \mathrm{~V}$.

The phase transition temperature, latent heat value, thermal reliability and thermal durability of the phase change energy storage composites were obtained by DSC and TG analyses. The tests were carried out in the analysis and testing centre of Southeast University, and the instrument model was NETZSCH STA 449F3. The samples were tested under $\mathrm{N}_{2}$ atmosphere. The temperature range was $30 \sim 1200^{\circ} \mathrm{C}$, and the heating rate was $10 \mathrm{~K} / \mathrm{min}$.

The thermal conductivity of the phase change energy storage composites, which were added to gypsum and cement at mass fractions of 10\%, $20 \%$ and $30 \%$, was tested by a DRE-IC unsteady thermal sensor. The DRE-IC unsteady thermal sensor is manufactured by Xiangtan City Instrument Co., Ltd. The thermal conductivity of the test piece was tested at room temperature by using the transient planar heat source method. 
To further study the influence of the phase change energy storage composites on the macroscopic properties of cement, the compressive and flexural strengths of cement paste and gypsum paste with $10 \%, 20 \%$ and $30 \%$ of the phase change energy storage composite (paraffin:red mud=0.55:0.45) were determined. The water to cement ratio of the cement and gypsum pastes was 0.4 , and the samples were cured for $28 \mathrm{~d}$ in a standard conservation room. The testing instrument was a cement strength testing machine, and the model is AEC-201.

\section{Results and discussion}

\subsection{SEM analysis of the particle morphology}

Fig. 1 demonstrates the micro-scale morphologies of paraffin, red mud, and the paraffin/red mud phase change energy storage composite. As shown in Fig. 1(a), the paraffin surface is relatively smooth and compact and mainly in the form of disc-like shapes. Fig. 1(b) shows the rather vague outline without a fixed shape of red mud with different particle sizes. There are pores between the particles. Compared with the pores between the particles observed in Fig. 1(b), there are few visible pores after paraffin impregnation, as seen in Fig. 1(c), Fig. 1(d), Fig. 1(e), and Fig. 1(f), indicating paraffin is well impregnated into the red mud pores.

\subsection{Laser particle size analyser analysis of the particle size distribution}

Fig. 2 shows the particle size analysis of the red mud, paraffin and paraffin/red mud phase change composite. As we can observe from Fig. 2(a), the mean particle sizes of the red mud and paraffin are $3.949 \mu \mathrm{m}$ and $300.144 \mu \mathrm{m}$, respectively. The particle size range of red mud is from $0.566 \sim 16.006 \mu \mathrm{m}$. The $1.056 \sim 3.178 \mu \mathrm{m}$ range accounts for $40 \%$ of the total, and the $3.178 \sim 7.799 \mu \mathrm{m}$ range accounts for $40 \%$. The particle size range of paraffin is from $3 \sim 500 \mu \mathrm{m}$, and the range of $65 \sim 500 \mu \mathrm{m}$ accounts for $99.145 \%$ of the particles. The raw material particles are evenly distributed. The particle size gradation of the phase change composite is very close, as shown in Fig. 2(b), and the particle size distribution mainly concentrates in the 83 $\mu \mathrm{m} \sim 633 \mu \mathrm{m}$ range, which accounts for $80 \%$ of the total $(83.572 \sim 633 \mu \mathrm{m}$ range accounts for $80 \%$ of 1\#, 112.898 627.394 $\mu \mathrm{m}$ range accounts for $80 \%$ of 2\#, 
134.204 625.396 $\mu \mathrm{m}$ range accounts for $80 \%$ of $3 \#$ and $141.939 \sim 632.301 \mu \mathrm{m}$ range accounts for $80 \%$ of $4 \#$ ). As seen from the results, the particle size of the paraffin/red mud phase change composite is close to that of paraffin but slightly larger. The main reason is that paraffin is not fully incorporated into the red mud pores during heating and melting. Paraffin accumulates on the surface of the red mud, resulting in the increased red mud particle size. Duo to which, as the paraffin content increases, the particle size tends to increase.

\subsection{BET pore size analysis}

Fig. 3 illustrates the $\mathrm{N}_{2}$ adsorption-desorption isotherms of the raw materials. Low-temperature liquid nitrogen adsorption tests mainly include two stages of adsorption and desorption. The adsorption stage is mainly composed of monolayer adsorption, multilayer adsorption and capillary condensation, and the desorption stage is mainly for de-coagulation and evaporation (large pores after the first pores). The adsorption/desorption curves contain red mud pore structure information. The obtained results are shown and summarized in Fig. 3(a). When the $\mathrm{P} / \mathrm{P}_{0}$ is $0 \sim 0.2$, the amount of red mud adsorbed increases with the increase in pressure, indicating the existence of a microporous structure. For $0.2<\mathrm{P} / \mathrm{P}_{0}<0.9$, the isothermal adsorption curve of red mud changes rapidly and does not coincide with the desorption curve. The main reason for this result may be the condensation of capillary pores and the presence of more mesopores. For P/P0> 0.9, the red mud adsorption curve increases sharply, indicating that there are still large pores in the red mud. As shown in Fig. 3(a) and (b), the pore surface area, pore size, and total pore volume of red mud are 55.054 $\mathrm{m}^{2} / \mathrm{g}, 2 \sim 25 \mathrm{~nm}$ and $0.163 \mathrm{~m}^{3} / \mathrm{g}$, respectively. The micropore size is $0.01835 \mathrm{~m}^{3} / \mathrm{g}$, and the micropore size accounts for approximately $11 \%$ of the pore size distribution. These results indicate that the red mud has few microporous structures and mainly contains mesoporous and macroporous structures, which can be used as a matrix material to allow paraffin to flow into the pores.

Fig. 4 demonstrates the isotherm and pore size distribution curves of the paraffin/red mud phase change energy storage composites. As we can see from Fig. 4 
(a) and (b), the surface area results are $0.192 \mathrm{~m}^{2} / \mathrm{g}(1 \#), 0.965 \mathrm{~m}^{2} / \mathrm{g}(2 \#), 0.188 \mathrm{~m}^{2} / \mathrm{g}$ (3\#), and $0.067 \mathrm{~m}^{2} / \mathrm{g}$ (4\#). The pore size distributions of the paraffin/red mud phase change energy storage composites are mainly in the range of 1 27 nm. The analysis data shows that with the addition of paraffin, the total pore volume of the paraffin/red mud phase change energy storage composite gradually decreases, and the specific surface area also decreases, indicating that paraffin flows into the red mud pores with mixing and heating. The analysis also shows that red mud can be used as a porous substrate and adsorptive material.

\subsection{FT-IR analysis of the phase change energy storage composites}

The chemical compatibility between the raw and phase change materials was determined by an FT-IR spectroscopy analysis method. The experimental test results are shown in Fig. 5.

Fig. 5 shows the FT-IR spectra of the raw materials and paraffin/red mud phase change energy storage composites. The spectra clearly show that the infrared peaks of the paraffin/red mud phase change energy storage composites retain some characteristic absorption peaks of red mud and paraffin, and the peak shapes are basically similar. The characteristic absorption peaks and peak trends of the raw materials and paraffin/red mud phase change energy storage composites can be seen in Table 2. It can be seen from the figure and table that the paraffin peaks are generally sharp; the peaks are large and sharp at most wave numbers, and the peaks are smoother at a few wave numbers. These peaks represent $\mathrm{O}-\mathrm{H}$ bonding $\left(3605 \mathrm{~cm}^{-1}\right.$ and $\left.2634 \mathrm{~cm}^{-1}\right), \mathrm{C}=\mathrm{O}$ bonding $\left(1896 \mathrm{~cm}^{-1}\right.$ and $\left.1721 \mathrm{~cm}^{-1}\right), \mathrm{C}-\mathrm{O}$ bonding $\left(1377 \mathrm{~cm}^{-1}\right.$, $1303 \mathrm{~cm}^{-1}$, and $\left.1129 \mathrm{~cm}^{-1}\right)$, and $=\mathrm{C}-\mathrm{H}$ and Ar-H stretching $\left(889 \mathrm{~cm}^{-1}, 730 \mathrm{~cm}^{-1}\right.$, and $\left.720 \mathrm{~cm}^{-1}\right)$. The peak of the raw red mud material is smooth, and the characteristic peaks of red mud are shown in Table 2. The peaks represent the bending vibration of $\mathrm{C}-\mathrm{H}$ (1500-400 $\left.\mathrm{cm}^{-1}\right)$, bending stretching vibration of $\mathrm{C}=\mathrm{O}, \mathrm{C} \equiv \mathrm{N}$, and $\mathrm{C} \equiv \mathrm{C}$ (2400-1500 $\left.\mathrm{cm}^{-1}\right)$, and O-H and N-H stretching (4000-2400 $\left.\mathrm{cm}^{-1}\right)$. As seen from Fig. 3-5(b), the characteristic peak positions and shapes of the paraffin/ red mud phase change energy storage composites are basically the same with common characteristic 
peaks at $2918 \mathrm{~cm}^{-1}, 2849 \mathrm{~cm}^{-1}$ and $1473 \mathrm{~cm}^{-1}$, and $720 \mathrm{~cm}^{-1}$. The peak values of the four different proportions of the phase change composites are also large and sharp near $2956 \mathrm{~cm}^{-1}, 2918 \mathrm{~cm}^{-1}$, and $2849 \mathrm{~cm}^{-1}$. Among the sharper peaks and smoother peaks of 1\#, 2\#, 3\# and 4\#, at $461 \mathrm{~cm}^{-1}(3 \#), 804 \mathrm{~cm}^{-1}$ and $463 \mathrm{~cm}^{-1}(4 \#)$, there is a slight difference between $804 \mathrm{~cm}^{-1}$ and $463 \mathrm{~cm}^{-1}$, which is caused by the difference in the paraffin content. The peaks represent the stretching vibration of O-H $\left(2956 \mathrm{~cm}^{-1}\right.$, $2918 \mathrm{~cm}^{-1}$, and $2849 \mathrm{~cm}^{-1}$ ), unsaturated bond stretching vibrations of $\mathrm{C}=\mathrm{C}$ and $\mathrm{N}=\mathrm{O}$ $\left(1637 \mathrm{~cm}^{-1}, 1587 \mathrm{~cm}^{-1}, 1473 \mathrm{~cm}^{-1}\right.$, and $\left.1412 \mathrm{~cm}^{-1}\right)$, and bonding of $=\mathrm{C}-\mathrm{H}$ and $\mathrm{Ar}-\mathrm{H}$ $\left(994 \mathrm{~cm}^{-1}, 804 \mathrm{~cm}^{-1}, 770 \mathrm{~cm}^{-1}, 720 \mathrm{~cm}^{-1}, 694 \mathrm{~cm}^{-1}, 660 \mathrm{~cm}^{-1}\right.$, and $\left.621 \mathrm{~cm}^{-1}\right)$.

The characteristic peaks of the raw materials are not changed in the phase change composite. A comparison of the characteristic spectra of the raw materials and phase change composites shows that there are no new peak shapes in the FT-IR spectra of the four types of paraffin/red mud phase change energy storage composites. The peak locations are exactly superimposed on the raw material and paraffin peaks. Therefore, the different mass ratios of paraffin embedded in red mud to obtain the phase change energy storage composites did not generate new substances. The chemical compositions did not change, and the phase change energy storage composites are stable.

3.5 XRD analysis of the phase change energy storage composites

The XRD patterns of the paraffin, red mud, and phase change materials are shown in Fig. 6. As seen from Fig. 6(a), red mud mainly contains halloysite-10A, $\mathrm{Na}_{2} \mathrm{H}_{2} \mathrm{SiO}_{4}\left(\mathrm{H}_{2} \mathrm{O}\right)_{4}$, laumontite, $\mathrm{C}_{28} \mathrm{H}_{30} \mathrm{O}_{4}, \quad\left(\mathrm{C}_{3} \mathrm{H}_{6}\right)_{\mathrm{x}}, \mathrm{Na}_{3} \mathrm{FeS}_{3}$, pyrite, opal and cancrinite. Fig. 6(b) shows the XRD pattern of paraffin; there are two strong diffraction peaks. The main elements in paraffin are $\mathrm{C}, \mathrm{H}$, and $\mathrm{O}$, and the main minerals are $\left(\mathrm{CH}_{2}\right)_{\mathrm{x}}, \mathrm{C}_{46} \mathrm{H}_{94}$ and $\mathrm{C}_{16} \mathrm{H}_{34} \mathrm{O}$. Diffraction peaks for the lattice spacing of the phase change composites (Fig. $6(\mathrm{c})$ ) are observed at $2 \theta=21.590^{\circ}, 23.408^{\circ}, 27.314^{\circ}$, $30.425^{\circ}$, and $32.526^{\circ}$ (paraffin:red mud ratio=0.4:0.6); $2 \theta=21.688^{\circ}, 24.396^{\circ}$, and $26.834^{\circ}$ (paraffin:red mud ratio $=0.45: 0.55$ ) $; 2 \theta=20.821^{\circ}, 21.580^{\circ}, 24.071^{\circ}, 26.617^{\circ}$, $29.542^{\circ}$, and $33.334^{\circ}$ (paraffin:red mud ratio=0.5:0.5); and $2 \theta=21.525^{\circ}, 24.017^{\circ}$, 
$24.342^{\circ}, 25.263^{\circ}, 26.563^{\circ}, 29.380^{\circ}$, and $33.334^{\circ}$ (paraffin:red mud ratio=0.55:0.45). The paraffin/red mud phase change energy storage composites contain all the peaks of paraffin and red mud, but the peak intensities are relatively lower in comparison with those of paraffin and red mud. The results indicate that the red mud/paraffin phase change energy storage materials are simply a combination of paraffin and red mud, and no new substance was produced. The phase change energy storage materials meet the requirements.

\subsection{LRS of the phase change energy storage composites}

The Raman spectra of the raw materials and paraffin/red mud phase change energy storage composites are shown in Fig. 7. Fig. 7(a) and (b) shows that red mud has two characteristic peaks at $1588.82 \mathrm{~cm}^{-1}$ and $2849.90 \mathrm{~cm}^{-1}$, and the characteristic peaks of paraffin are at $1063 \mathrm{~cm}^{-1}, 1132 \mathrm{~cm}^{-1}, 1295 \mathrm{~cm}^{-1}, 1440 \mathrm{~cm}^{-1}, 634 \mathrm{~cm}^{-1}, 426$ $\mathrm{cm}^{-1}$, and $298 \mathrm{~cm}^{-1}$.

Fig. 7(c) shows that the Raman peaks of the phase change composites are at 291 $\mathrm{cm}^{-1}, 405 \mathrm{~cm}^{-1}$, and $615 \mathrm{~cm}^{-1}(2 \#) ; 291 \mathrm{~cm}^{-1}, 405 \mathrm{~cm}^{-1}, 610 \mathrm{~cm}^{-1}, 615 \mathrm{~cm}^{-1}$, and 1076

$\mathrm{cm}^{-1}(3 \#)$; and $300 \mathrm{~cm}^{-1}, 404 \mathrm{~cm}^{-1}$, and $556 \mathrm{~cm}^{-1}(4 \#)$. The shapes and peaks of the three phase transition energy storage materials with different proportions are similar, and no new characteristic peak was produced. Therefore, the materials are chemically mixed without a chemical reaction and are chemically stable.

\subsection{Thermal properties of the phase change energy storage composites}

Fig. 8 and Fig. 9 show the DSC and TG curves, respectively, of the raw materials and paraffin/red mud phase change energy storage composites. Fig. 8(a) shows the DSC results for paraffin and red mud. Fig. 8(b) shows the DSC results of the paraffin/red mud phase change energy storage composites. Fig. 8(a) and (b) shows that the DSC curves of red mud, paraffin and the paraffin/red mud phase change energy storage composites are basically smooth endothermic curves as the temperature increases, and the DSC diagrams of the paraffin/red mud phase change energy storage composites with different proportions are similar. The DSC curves of 
red mud and paraffin have two exothermic peaks at $273.75^{\circ} \mathrm{C}$ and $666.11^{\circ} \mathrm{C}$ (red mud) and $70^{\circ} \mathrm{C}$ and $450^{\circ} \mathrm{C}$ (paraffin). Fig. 8(b) also shows that there are exothermic peaks for the paraffin/red mud phase change energy storage composites at approximately $80.23^{\circ} \mathrm{C}$ and $463.91^{\circ} \mathrm{C}(1 \#) ; 74.72^{\circ} \mathrm{C}$ and $466.14^{\circ} \mathrm{C}(2 \#) ; 79.34^{\circ} \mathrm{C}$ and $468.32^{\circ} \mathrm{C}(3 \#)$; and $84.66^{\circ} \mathrm{C}$ and $468.58^{\circ} \mathrm{C}(4 \#)$, which are very close to one peak of paraffin $\left(450^{\circ} \mathrm{C}\right)$. Compared with that of the raw materials, the exothermic peak temperature of the phase change energy storage composite is close to the peak value of paraffin. Thus, the peak temperature is greatly affected by paraffin, and red mud has little influence on the temperature.

The measured TG curves of paraffin, red mud and the four paraffin/red mud phase change energy storage composites are shown in Fig. 9. Red mud has a higher rapid weight loss temperature of approximately $600^{\circ} \mathrm{C}$, and the quantity was reduced by approximately $10.62 \%$. The paraffin quantity decreased by approximately $97.84 \%$ at $480^{\circ} \mathrm{C}$ based on the curve of paraffin. The quantity of the paraffin/red mud phase change energy storage composites began to decrease at approximately $70^{\circ} \mathrm{C}$ and decreased rapidly in the range of $250 \sim 470^{\circ} \mathrm{C}$, and then the mass remained nearly constant after approximately $470^{\circ} \mathrm{C}$. The paraffin/red mud phase change energy storage composite weights had the following trends: (1\#) decreased by $44.45 \%$ at $470^{\circ} \mathrm{C}$ and $1.82 \%$ at $470{ }^{\circ} \mathrm{C} \sim 1200^{\circ} \mathrm{C}$; (2\#) decreased by $46.96 \%$ at $470^{\circ} \mathrm{C}$ and $3.18 \%$ at $470 \sim 1200^{\circ} \mathrm{C}$; (3\#) decreased by $56.90 \%$ at $470^{\circ} \mathrm{C}$ and $1.57 \%$ at $470 \sim 1200^{\circ} \mathrm{C}$; and (4\#) decreased by $60.36 \%$ at $470^{\circ} \mathrm{C}$ and $1.70 \%$ at $470 \sim 1200^{\circ} \mathrm{C}$. Based on the above analysis results, red mud has a rapid decline in weight and an endothermic peak within the temperature range of $250 \sim 300^{\circ} \mathrm{C}$. This is because red mud contains bound water and organic matter, and after the evaporation of bound water and volatile organic compounds (the hydroxyl groups in halloysite-10A, $\mathrm{C}_{28} \mathrm{H}_{30} \mathrm{O}_{4}$ and $\left.\left(\mathrm{C}_{3} \mathrm{H}_{6}\right)_{\mathrm{x}}\right)$ at approximately $300 \sim 600^{\circ} \mathrm{C}$, red mud showed no obvious weight loss. The same was observed in the composites because red mud consists of some water-containing minerals, and as the temperature rises, the water gradually evaporates. When the temperature was above $600^{\circ} \mathrm{C}$, the weight was basically unchanged, and little weight loss is seen in the results. This is due to the carbonate in the red mud, which begins to 
decompose and produce a gas. However, the exothermic peak values of the phase change composites with different proportions are basically the same, and the exothermic peak temperatures are larger than that of red mud and are mainly affected by paraffin. At a temperature of $450^{\circ} \mathrm{C}$, paraffin has a significant endothermic peak, as shown in Fig. 9(a). This is almost the same as that of the phase-change composites, i.e., at $470^{\circ} \mathrm{C}$.

The phase change energy storage composites were tested to determine their durability and stability under the same thermal cycling conditions. As shown in Fig. 10 , the cycles were conducted in the temperature range of $50 \sim 100^{\circ} \mathrm{C}$. The exothermic peaks of the phase change energy storage composites are $80.40^{\circ} \mathrm{C}(1 \#), 77.27^{\circ} \mathrm{C}(2 \#)$, $80.41^{\circ} \mathrm{C}(3 \#)$, and $81.25^{\circ} \mathrm{C}(4 \#)$. The peak temperature changes very little compared with the results before thermal cycling. The results indicate that the chemical structures of the phase change energy storage composites are durable. The chemical structure did not change, and this implies that paraffin and red mud are simply in a physical mixture without chemically reacting.

\subsection{Thermal conductivity of the phase change energy storage composites}

The effect of the amount of the phase change composite on thermal conductivity was studied in this experiment. The thermal conductivity of gypsum-based and cement-based phase change composites with 4 different fixed ratios changed with the addition of the paraffin/red mud phase change energy storage composites, as shown in Fig. 11. Each data point in the graph is the average of three parallel tests. Overall, the thermal conductivity of the gypsum-based phase change energy storage composites decreases nearly linearly as the amount of the phase change energy storage composite increases, showing a significant reduction in the thermal conductivity. There are two main reasons for the reduction, i.e., the phase change composite material has a lower thermal conductivity than gypsum, and the phase change materials can store heat.

The error range for the measured thermal conductivity values of the gypsum-based test blocks (Fig. 11(a), (b), (c) and (d)) added to red mud indicated that the change was not stable. Overall, there are two main reasons for the above 
phenomenon. First, the phase change composite materials are restricted by the effective heat storage density. Additionally, there are some inhomogeneities and inconsistencies in the distribution of the phase change composite particles in the samples of different batches, which may hinder the formation of a thermal conductive network. Fig. 11 shows the test results of the thermal conductivity of cement-based materials with different proportions. The thermal conductivity test results show that the thermal conductivity of the cement-based samples is inversely proportional to the amount of phase change material added and that the thermal conductivity is lower under dry conditions than that under wet conditions. The thermal conductivity of the cement sample without the phase change composite is high, and the thermal conductivity decreases as the phase change composite amount increases. When the proportion of the phase change composite is more than $10 \%$, the thermal conductivity slowly declines. The reason for the decrease in the thermal conductivity in the early stage is that the heat capacity of the pure cement sample may be small, and the heat energy stored or released by the cement is small. After the phase change composite is added, the phase change material's phase change begins due to the significant heat capacity storage of the phase change composite, causing the thermal conductivity of the cement-based test block to decrease rapidly. With the increase in the amount of the phase change composite in the later stage, the phase change composite's energy storage gradually becomes stable.

Based on the above results, the thermal conductivity of dry samples is lower than that of wet samples in the same proportion. In the wet state, the liquid water will replace the air in the micropores. Under normal temperature and pressure, the thermal conductivity of liquid water is much larger than the thermal conductivity of air. Therefore, the thermal conductivity of the moisture-containing material will be greater than the thermal conductivity of the dried material. Under the same conditions, the thermal conductivity of the cement-based sample is larger than the thermal conductivity of the gypsum-based sample, which is mainly because the thermal conductivity of gypsum is less than that of cement. 
3.9 Mechanical strength of the gypsum-based and cement-based materials

Fig. 13 demonstrates the compressive and flexural strengths of the cement-based composites. As shown in Fig. 13(a), no obvious flexural strength change is observed in the cement-based materials after adding $10 \%$ and $20 \%$ of the phase change composite material. However, when $30 \%$ was added, the compressive strength of the resultant material decreased significantly, i.e., a decline of nearly $40 \%$ occurred.

The phase change energy storage composites have a great influence on the flexural strength, and the flexural strength decreased nearly $50 \%$ compared with that of the cement-based materials when $10 \%$ of the phase change composite material was added. This is because the phase change composite materials contain red mud, while red mud is alkaline, which affects the cement material pore solution alkalinity. The pore solution alkalinity affects the hydration, hardening, hydration reaction course, and hydration mechanism of cement, which are related to the stability of hydration products in the hardened cement body ${ }^{[22-23]}$ and affect the macroscopic properties of cement.

Fig. 14 shows the compressive and flexural strengths of the gypsum-based materials. Adding $10 \%$ of the phase change composite material has little influence on the compressive strength but has a great effect on the flexural strength. When adding $20 \%$ and $30 \%$ phase change composite material, the compressive and flexural strengths are obviously decreased. This result is due to the poor compatibility between the phase change composite and the gypsum crystal, which increases the number of voids and defects. Another reason is that the compressive and flexural strengths of the phase change composite are small.

\section{Conclusions}

In this paper, paraffin/red mud phase change energy storage composites were prepared through a two-step procedure. Based on the presented experimental research, the following conclusions can be drawn:

(1) The SEM and FT-IR results show that paraffin can be well incorporated in red mud pores, and the two are compatible. Thermogravimetric (TG) analysis results showed that the phase change energy storage composites have good thermal stability 
performance.

(2) The fabricated paraffin/red mud phase change energy storage composite melting temperatures varied from $75^{\circ} \mathrm{C} \sim 85^{\circ} \mathrm{C}$, and the latent heat values were approximately $25 \sim 40 \mathrm{~J} / \mathrm{g}$.

(3) Compared with the pure cement and gypsum blocks, the compressive and flexural strengths of cement-based and gypsum-based blocks with the phase change composite material decreased. The compressive strength decreased rapidly when increasing the proportion of the phase change composites to $30 \%$.

(4) The heat storage performance of cement-based and gypsum-based materials can be improved remarkably with the addition of a phase change energy storage composite replacement.

\section{Acknowledgements}

The authors gratefully acknowledge financial support from the National Natural Science Foundation of China (51778613) and the Fundamental Research Funds for the Central Universities (2017XKZD09). 


\section{References}

[1] Shaikh S, Lafdi K. C/C composite, carbon nanotube and paraffin wax hybrid systems for the thermal control of pulsed power in electronics. Carbon, 2010, 48(3):813-824.

[2] Laaouatni A, Martaj N, Bennacer R, et al. Phase change materials for improving the building thermal inertia. Energy Procedia, 2017, 139:744-749.

[3] Zhang Z, Shi G, Wang S, Fang X, Liu X. Thermal energy storage cement mortar containing n-octadecane/expanded graphite composite phase change material. Renew Energy, 2013,50:670-5.

[4] Zhang wenhua, Zhang Yunsheng, Research on the static and dynamic compressive properties of high performance cementitious composites (HPCC) containing coarse aggregate, Archives of Civil and Mechanical Engineering, 2015, 15(3): 711-720.

[5] Xu B, Li Z. Paraffin/diatomite composite phase change material incorporated cement-based composite for thermal energy storage. Applied Energy, 2013, 105(2):229-237.

[6] Li Benxia, Liu Tongxuan, Hu Luyang, et al. Fabrication and properties of microencapsulated paraffin@ $\mathrm{SiO}_{2}$ phase change composite for thermal energy storage. Sustainable Chemistry \& Engineering,2013,1( 3) : 374-380.

[7] Ghalambaz M, Doostani A, Chamkha A J, et al. Melting of Nanoparticles-Enhanced Phase-Change Materials in an Enclosure: Effect of Hybrid Nanoparticles. International Journal of Mechanical Sciences, 2017.

[8] Jegadheeswaran S,Pohekar S D. Exergy analysis of particle dispersed latent heat thermal storage system for solar water heaters. Journal of Renewable and Sustainable Energy, 2010, 2(2):1-17.

[9] Zeng J L, Chen Y H, Shu L, et al. Preparation and thermal properties of exfoliated graphite/erythritol/mannitol eutectic composite as form-stable phase change material for thermal energy storage. Solar Energy Materials \& Solar Cells, 2018, 178:84-90.

[10] Jiao C, Ji B, Fang D. Preparation and properties of lauric acid-stearic acid/expanded perlite composite as phase change materials for thermal energy storage. Mater Lett, 2012,67:352-4. 
[11] Zhiyong Liu, Dan Hu, Henglin Lv, Yunsheng Zhang. Mixed mill-heating fabrication and thermal energy storage of diatomite/paraffin phase change composite incorporated gypsum-based materials. Applied Thermal Engineering, 2017,118: 703-713.

[12] Y. Wang, H. Zheng, H.X. Feng, D.Y. Zhang. Effect of preparation methods on the structure and thermal properties of stearic acid/activated montmorillonite phase change material. Energy and Buildings, 2012, 47: 467-473.

[13] Guo X, Zhang S, Cao J. An energy-efficient composite by using expanded graphite stabilized paraffin as phase change material. Composites Part A Applied Science \& Manufacturing, 2018.

[14] PINCEMIN S, OLIVERS R, PY X, et a1. Highly conductive composites made of phase change materials and graphite for thermal storage. Solar Energy Materials \& Solar Cells, 2008, 92: 603-613.

[15] Alam, S., Das, B.K., Das, S.K. Dispersion and sedimentation characteristics of red mud. Journal of Hazardous, Toxic, and Radioactive Waste. 2018, 22 (4), 1-10.

[16] Alam S, Das S K, Rao B H. Characterization of Coarse Fraction of Red Mud as a Civil Engineering Construction Material. Journal of Cleaner Production, 2017, 168:679-691.

[17] Tsakiridis P E, Agatzini-Leonardou S, Oustadakis P, Red Mud Addition in the Raw Meal for the Production of Portland Cement Clinker. Journal of Hazardous Materials, 2004(116):103-110.

[18] Senff L, Hotza D, Labrincha J A. Effect of Red Mud Addition on the Rheological Behaviour and on Hardened State Characteristics of Cement Mortars. Construction and Building Materials, 2011(25):163-170.

[19] Pulford I D, Hargreaves J S J, et al. Carbonised red mud-A new water treatment product made from a waste material. Journal of Environmental Management, 2012, 100(10):59-64.

[20] Akin I, Arslan G, Tor A, et al. Arsenic(V) removal from underground water by magnetic nanoparticles synthesized from waste red mud. Journal of Hazardous Materials, 2012, 235-236(0):62-68. 
[21] Wang X, Qu Y, Hu W, et al. Particle characteristics and rheological constitutive relations of high concentration re mud. Journal of China University of Mining and Technology, 2008, 18(2):266-270.

[22] Hou, D., Zhao, T., Ma, H., \& Li, Z.. Reactive molecular simulation on water confined in the nanopores of the calcium silicate hydrate gel: structure, reactivity, and mechanical properties. The Journal of Physical Chemistry C, 2015, 119(3), 1346-1358.

[23] Zhang wenhua, Zhang Yunsheng, Apparatus for monitoring the resistivity of the hydration of cement cured at high temperature, Instrumentation Science \& Technology, 2017, 45(2):151-162. 